\title{
Josep Pla y Lytton Strachey: retratos en paralelo*
}

\author{
Joaquim ESPINÓS FELIPE \\ Universitat d'Alacant \\ ximo.espinos@ua.es
}

\begin{abstract}
RESUMEN
Lytton Strachey y Josep Pla son autores con una personalidad creadora diferenciada, pero también con importantes puntos de contacto. Pla sentía una gran admiración por el escritor inglés, fundador de la llamada nueva biografía. Strachey renovó el género gracias a su mirada crítica y a su instinto literario, atento a los detalles, a la síntesis, a la ironía. La eficacia narrativa de sus textos y su penetración psicológica acortaron la distancia entre biografía y novela. Todas estas son cualidades presentes también en la obra de Josep Pla. Cuando Pla conoció la obra de Strachey y la de los otros autores de la nueva biografía, era un joven escritor que había decidido el rumbo que su obra debía tomar: el del memorialismo. En su voluntad de dejar testimonio de su época, las biografías ya habían empezado a ocupar un papel importante, que a lo largo de su producción no haría sino crecer. Parece razonable pensar que ese conocimiento pudo ser para él una confirmación en la opción literaria que había elegido, así como un estímulo a lo largo de los años de insistencia en el género biográfico.
\end{abstract}

Palabras clave: Josep Pla, Lytton Strachey, nueva biografía, literatura catalana.

[Recibido, marzo 2014; aprobado, enero 2015]

Josep Pla and Lytton Strachey: parallel portraits

\begin{abstract}
Lytton Strachey and Josep Pla are authors with distinct creative personalities, but also with important points of contact. Pla felt a great admiration for the English writer, founder of the so-called New Biography. Strachey renewed the genre thanks to his critical eye and his literary instinct, attentive to detail, to synthesis, to irony. The narrative effectiveness of his texts and their psychological penetration shortened the distances between biography and novel. All these qualities are also present in the work of Josep Pla. When Pla read Strachey's work and that of the other New Biography authors, he was a young writer who had already decided the direction that his work should take: the memoirs. In his desire to leave a record of his time, biographies had already begun to play an important role, which would grow in relevance throughout his writing career. It seems reasonable to think that the reading of Strachey's work and that of the other New Biography authors could offer Pla confirmation in his chosen literary option as well as encouragement throughout his years of dedication to the biographical genre.
\end{abstract}

Keywords: Josep Pla, Lytton Strachey, New Biography, Catalan Literature.

* Este artículo forma parte del proyecto de investigación "El conocimiento del otro: biografías y retratos en la literatura catalana del siglo XX", FFI2011-26027, 2012-2014, concedido por el Ministerio de Educación y Ciencia. 


\section{Lytton Strachey y la nueva biografía}

Existe unanimidad crítica en considerar 1918, año en que Lytton Strachey publica Eminent Victorians, como el punto de partida de lo que se ha dado en llamar nueva biografía. A partir de entonces, ya nada fue igual en el género biográfico. Cierto que Strachey no surgió de la nada, sino que es el producto de una época, la posterior a la I Guerra Mundial, que tuvo que replantearse a fondo la herencia recibida. Daniel Madelénat, en su estudio clásico sobre el tema, divide la historia de la biografía en tres grandes paradigmas: el clásico, el romántico y el moderno. Éste último, inaugurado por Strachey, se caracterizaría por dibujar "une image complexe de l'homme, en l'absence de tout dogme imposé, ou de toute theorie hegémonique" (1984: 65). La nueva biografía nace, pues, bajo el signo de la desmitificación,

El libro de Strachey tuvo un éxito sensacional y contribuyó a aumentar la popularidad de la biografía entre el público inglés primero y entre el europeo después. Impulsada por el marasmo de la novela y la consiguiente demanda de hechos y personajes reales, la biografía se convirtió, durante el periodo de entreguerras, en el género de moda. En Francia el principal impulsor fue André Maurois, en el ámbito germano destaca la obra de Emil Ludwig i Stefan Zweig. Junto con Strachey, configuran el cuarteto de los principales renovadores del género.

En el prefacio de Eminent Victorians, Strachey expone su deseo de ilustrar la historia de la Época Victoriana de manera fragmentaria, no mediante un relato lineal y totalizador, sino seleccionando "algún espécimen representativo", elegido por "simples motivos de conveniencia y artísticos", y manteniendo, siempre, la "propia libertad de espíritu". (Strachey 1998: 25). Cierto que, los personajes elegidos -el cardenal Manning, Florence Nightingale, Thomas Arnold y el general Gordon- no obedecen al simple capricho, sino que fueron muy populares en su tiempo, y representaban sectores fundamentales de la cultura y la sociedad victoriana: la iglesia, el ejército, la educación, la sanidad. La manera distante cuando no irónica con la que Strachey los aborda, dista mucho del tono hagiográfico dominante en el biografismo anterior ${ }^{1}$. Posteriormente Strachey escribió dos biografías largas, Queen Victoria, de 1921 y Elizabeth and Essex, de 1928. En su último libro, Portraits in Miniature, de 1931, repetiría la fórmula breve de Eminent Victorians, esta vez aplicada a un período más largo de la historia inglesa.

Además de la mirada crítica hacia los personajes tratados, otra de las particularidades de la nueva biografía es su acercamiento a las maneras literarias. Recurramos de nuevo al inagotable prefacio de Eminent Victorians:

Entre nosotros, la más delicada y refinada de todas las ramas del arte de la escritura se ha relegado a los aprendices de las letras; no nos hemos parado a pensar en que quizá es tan difícil escribir una buena vida como vivirla. Aquellos dos gruesos volúmenes con los que es nuestra costumbre recordar a los muertos, ¿quién no conoce su masa de información mal digerida, el estilo descuidado, el tono de tedioso panegírico, la lamentable falta de selección, de independencia de criterio, de construcción? (Strachey 1998: 26).

\footnotetext{
${ }^{1}$ Isabel Burdiel (2000: 33-34) ha observado como Eminent Victorians representaba la culminación de un modelo de biografías breves muy popular en el siglo XIX, que tendrían las Vidas paralelas de Plutarco como modelo. El libro de Strachey contribuyó a encumbrar y consolidar ese tipo de aproximación fragmentaria a las diferentes épocas históricas.
} 
El fragmento no tiene desperdicio, y contiene muchas de las claves de la aportación de Strachey al arte de la biografía. En primer lugar, destacaríamos la importancia del estilo, que en su obra alcanza cotas de indudable excelencia, tal y como han sido reconocido ampliamente por la crítica. Strachey pone también de relieve la importancia de la selección y de la construcción dentro del relato biográfico. Y esto nos sitúa en la órbita de la hibridación de la nueva biografía con la novelística contemporánea, y en especial, con la novela psicológica y sus técnicas introspectivas. La nueva biografía buscará también profundizar en las interioridades, en las motivaciones profundas de sus personajes. Para ello, Strachey recurre a elementos inspirados en las teorías freudianas, como la importancia de la infancia como origen de la personalidad adulta, la ambivalencia y las motivaciones inconscientes de sus personajes.

Junto con el interés por indagar en las galerías de la conciencia, los nuevos biógrafos harán uso también de la imaginación para rellenar los huecos dejados por la historia y darle al conjunto una unidad de composición. En ocasiones, esta libertad imaginativa vulnera la fidelidad que el género debe a los hechos históricos. Virginia Woolf, compañera del grupo de Bloomsbury y amiga personal de Strachey, abordó lúcidamente en sus ensayos el tema de las conflictivas relaciones de la nueva biografía con la historia. En "The New Biography" (1927), al referirse a la excesiva fidelidad de los biógrafos victorianos a los documentos históricos, afirmaba provocativamente que el biógrafo "has ceased to be a chronicler; he has become an artist" (1967: 231). Sin embargo, unos años después, en "The Art of Biography", de 1942, influída por los excesos imaginativos y la escasa documentación de Elizabeth and Essex, atenuará sus opiniones. El biógrafo nunca gozará de la libertad creativa del novelista o dramaturgo, siempre tiene que tener los pies bien anclados en la tierra de los hechos: "he is a craftsman, not an artist; and his work is not a work of art, but something betwixt and between" $(1967,227)$.

En España, a pesar de que no existía una tradición biográfica consolidada como en Francia o Inglaterra, la nueva biografía fue recibida con entusiasmo. Tal y como ha estudiado Serrano Asenjo (2002: 12), a finales de los años veinte el género biográfico vivió un auge inusitado. Las biografías noveladas, tal y como eran llamadas en aquel entonces las provenientes del nuevo modelo que acabamos de resumir, recibieron un decidido impulso editorial en el cual Ortega y Gasset jugó un papel protagonista. En la Revista de Occidente se reseñaron las obras de Strachey, el diario El Sol creó un apartado de "Biografías" y la editorial Espasa-Calpe impulsó la colección "Vidas españolas e hispanoamericanas del siglo XIX". Todo ello formaba parte del proyecto orteguiano de regeneración nacional, dentro del cual la publicación de biografías de sus figuras más ilustres podía ayudar a reforzar la autoestima colectiva y, en definitiva, a "vertebrar" España ${ }^{2}$. En ese empeño movilizó a algunos de los más importantes escritores del momento, tanto de la nueva generación como de la anterior (Serrano Asenjo 2002:12).

Otro aspecto de la promoción de una biografía hispánica fueron las traducciones de las obras de los principales representantes de la nueva biografía. Así, por citar algunos de los

\footnotetext{
${ }^{2}$ Personajes como el Duque de Osuna, Zumalacárregui, Bécquer, Castelar y Sor Patrocinio formaron parte de la colección.
} 
ejemplos más relevantes, Isabel y Essex y La reina Victoria de Strachey fueron vertidos al castellano en 1932 y 1934, respectivamente. De André Maurois se tradujo su Ariel o la vida de Shelley en 1930, y de Stefan Zweig, en 1929, Tres maestros. Balzac, Dickens, Dostiewsky. Ludwig, por su parte, se convirtió en el autor de moda, al ver la mayoría de sus obras traducidas al castellano.

\section{La recepción catalana de la nueva biografía}

El caso catalán resulta, en parte, paralelo al español. La literatura catalana tampoco contaba con una tradición sólida de literatura biográfica. La primera publicación contemporánea nace bajo el impulso del Modernisme, y pertenece a Francesc Gras i Elias, que edita entre 1909 y 1913 las cuatro series de Siluetes d'escriptors catalans del sigle XIX en la editorial de L'Avenç. A partir de entonces se sucede un goteo de obras, como las siluetes publicadas por Rovira i Virgili en diversos periódicos a partir de 1911 o los retratos de Plàcid Vidal recogidos en 1920 en Els singulars anecdòtics. En los años veinte y treinta se produce un punto de inflexión, con la aparición de una serie de colecciones fruto de la voluntad de reconstrucción nacional y de normalización literaria que regía en la literatura catalana en aquellos años. Entre el 1918 y el 1924, las Publicacions de l'Associació Protectora de l'Ensenyança Catalana editan una colección de biografías que se ocupan de personajes fundacionales de la cultura catalana, como Ramon Llull, Pi i Margall, Pau Claris, Jaume I o Jacint Verdaguer, escritas por intelectuales de reconocido prestigio. En los años treinta destacan las colecciones "Catalans d'ara" (1930-1932) y las pertenecientes a la Biblioteca Popular Barcino, que conservan los mismos planteamientos divulgativos e identitarios ${ }^{3}$.

A mediados de los veinte irrumpe el escritor que iba a dar un impulso decisivo al biografismo catalán. Hablamos de Josep Pla. Rovira i Virgili encargó al joven escritor, que por aquel entonces contaba con veintisiete años, una serie de Retrats a la ploma que aparecieron en el Annuari dels catalans (1924-1925). Algunos de estos retratos pasaron a sus dos primeros libros, Coses vistes (1925) y Llanterna màgica (1926), donde se unieron a otros inéditos, hasta configurar un total de treinta piezas. No era más que el inicio de una larga dedicación al género. Más tarde nos ocuparemos de él en extenso.

Destacaremos, por último, para finalizar esta rápida panorámica del biografismo catalán del primer tercio del siglo XX, los libros de retratos de Josep Maria Junoy (Gris i cadmi, 1926) y Doménech de Bellmunt (Figures de Catalunya, 1933; Homes de la terra, 1935) ${ }^{4}$.

La recepción de la nueva biografía en las letras catalanas coincide, como hemos podido observar, con un momento de auge del género por razones identitarias. En ese sentido, la situación catalana no difería de la de las letras españolas, en las que Ortega y Gasset había puesto las infraestructuras editoriales que dirigía o controlaba al servicio de su proyecto

\footnotetext{
${ }^{3}$ En la Biblioteca Popular Barcino predominan las biografías de reyes (Guifré I, Jaume I, Carles de Viana, Pere II, Ramon Berenguer IV i Pere III) y escritores (Teodor Llorente, Joan Maragall, Valentí Almirall, Joan Lluís Vives, Jacint Verdaguer, Narcís Oller i Joaquim Ruyra), pilares básicos en la articulación de un discurso nacional. Enric Balaguer (2012) ha estudiado de manera muy documentada la importancia de la literatura en la formación del imaginario nacional catalán.

${ }^{4}$ Queremos agradecer a Llorenç Soldevila la información que nos ha proporcionado sobre el biografismo catalán anterior a 1936.
} 
vertebrador de España. El terreno estaba pues abonado para que la moda biográfica prendiera también en Cataluña. El autor que allí gozó de mayor predicamento fue André Maurois, del cual se tradujeron varios volúmenes entre 1929 y $1935^{5}$. Incluso se contó con la visita de algunos de sus más eximios representantes. Así, el propio Maurois visitó Cataluña de la mano de Carles Soldevila, en octubre de 1933, invitado por la editorial Juventud y del Conferencia Club, del cual Soldevila era secretario ${ }^{6}$. Aquel mismo año, también Emil Ludwig pasó por Barcelona, invitado por la Generalitat.

Es hora que nos ocupemos ya de la relación de Josep Pla con la nueva biografía. Pla demuestra tener un interés y conocimiento amplio de sus principales representantes. A todos ellos, con la única excepción de Stefan Zweig, les dedica algún comentario a lo largo de su larga carrera como escritor. Tal y como observa Jordi Amat en el artículo que dedica a los inicios como biógrafo de Josep Pla (Amat 2006: 98-99), la primera muestra relevante de este interés la encontramos en un artículo publicado en La Veu de Catalunya a finales de 1929. En este artículo, titulado "André Maurois", Pla valora positivamente la obra del escritor francés, así como de de Ludwig. Sin embargo, de éste último mantuvo una opinión vacilante, tal y como podemos observar en la crítica feroz que le dedica en el retrato que realizó con motivo de su visita a Madrid en 1932 para impartir un ciclo de conferencias:

Un llibre que es llegeix molt d'aquest autor és el Napoleó. Fet amb refregits de quarta o cinquena mà, no arriba a la sola de la sabata del Napoleó de Jaques Bainville ni al capítols que dedica a aquest sinistre gran home Albert Sorel en la seva obra Europa i la Revolució francesa. I del Bismark, i del Lincoln i en general de les seves aparatoses biografies, que se n'hauria de dir? Quan hom pensa que en morir, ara fa poc, el mestre insuperable de la biografia, mister Lytton Strachey, els diaris del nostre país no en digueren ni una paraula, ni aquest bon señor té res traduït, hom queda veient visions (Pla 1970b: 435).

A pesar de la exageración de Pla - Isabel y Essex se tradujo en 1932, el mismo año en que escribió este retrato, y dos años más tarde La reina Victoria -, interesa resaltar su crítica a la moda Ludwig y su apuesta por el escritor inglés. ${ }^{7}$ Unos años más tarde, Pla reiterará su interés y admiración por Strachey. En 1955 escribía en el semanario Destino el siguiente elogio: "Per tenir una idea de l'època de la reina Victòria d'Anglaterra s'haurà de tornar sempre a les obres de Lytton Strachey, sobretot a la biografia de la famosa reina i a Eminent Victorians" (Pla 1977: 296-297). Pla tenía también en un elevado concepto del biografismo inglés anterior a Strachey. Le otorga la paternidad retrospectiva de la biografía novelada

\footnotetext{
${ }^{5}$ En concreto Viatge al país de les 36.000 voluntats, Els silencis del coronel Bramble, Climes, y Eduard VII i la seva època. Teresa Iribarren (2007) ha estudiado la recepción de Maurois en la Cataluña de aquellos años.

${ }^{6}$ Carles Soldevila continuó dando muestras en los años siguientes de su interés por la nueva biografía. Así, en los años cincuenta, delimita retrospectivamente el periodo de esplendor del género entre 1917 y 1939, al prologar las obras completas de Emil Ludwig:

Si para determinados espíritus delicados y de paladar goloso el mejor biógrafo de esta fecunda etapa puede ser el inglés Lytton Strachey con su aguda ironía, su lenguaje sabio y certero, su aparente candor, su malicia exquisitamente vestida de seda, para otros se llevará la palma el elocuente, cálido y dramático Zweig, y no faltará quien vote por el fino, inteligentísimo y ponderado Maurois, biógrafo de Disraeli i de Jorge Sand. Pero reconozcamos que serán numerosos los sufragios que en un plebiscito conquistaría Emil Ludwig con su Napoleón, su Lincoln y su Bismarck" (Soldevila 1956-1957: 17-18).

${ }^{7}$ Más tarde Pla cambiará de nuevo de criterio, valorando positivamente al alemán en el homenot que le dedica a Pau Casals (Pla 1972: 553-584). En 1971 afirmaba que su libro sobre el Kaiser Guillermo II era muy bueno (Pla) y lo mismo hará de su Goethe y el otrora denostado Napoleón (Pla 1983: 355).
} 
(Pla 1983: 354) y reitera en varias ocasiones su admiración por la Vida de Samuel Johnson, de James Boswell ${ }^{8}$.

\section{La producción biográfica de Josep Pla}

Creemos que ha quedado sobradamente acreditado el conocimiento e interés de Josep Pla por la nueva biografía en general y por la obra de Strachey en particular a lo largo de buena parte de su trayectoria creadora. Ahora cabría preguntarse: ¿este interés, se tradujo en algún tipo de influencia? Pensamos que sí, pero antes de entrar en ello, habría que dibujar, aunque sea sucintamente, las líneas maestras de la producción biográfica de Josep Pla.

No cabe duda que el biografismo ocupa un lugar preponderante en la producción del escritor de Palafrugell, aunque quizás su importancia haya quedado diluida en el resto de su extensa producción. De los cuarenta y siete volúmenes de su obra completa, once son biográficos de una manera explícita, y comprenden todas las modalidades de este tipo de escritura ${ }^{9}$. No debemos olvidar, además, tal y como observa Glòria Casals (1986: 124), la gran cantidad de notas y esbozos biográficos que podemos encontrar dispersos en el resto de su obra, en especial en sus diarios. Su dedicación al género biográfico le acompaña, como hemos visto antes, desde el inicio de su carrera de escritor. Después de los primeros retratos, publicados en Coses vistes y Llanterna mágica, sus siguientes incursiones en el género fueron en forma de biografía: en 1928 publica la del escultor Manolo Huguet, Vida de Manolo contada per ell mateix, y entre 1928 y 1930 la de Francesc Cambó en tres volúmenes, publicada en 1931 en un volumen unitario con el título de Vint-i-cinc anys de política catalanista: l'obra d'en Cambó. Hasta después de la guerra civil Pla no volvió a publicar un volumen biográfico. Se trata de la biografía de Santiago Rusiñol, publicada en 1942, ya en castellano: la censura franquista no daba otra opción.

Repitamos ahora la pregunta: ¿qué trazas de la obra de Strachey y de la nueva biografía pueden rastrearse en estas primeras obras, escritas en el momento de mayor impacto de su recepción, o en el resto de la vasta producción del que podemos considerar como el más destacado biógrafo de las letras catalanas? En nuestra opinión, la principal influencia puede haberse dado en el terreno de la literaturización de la escritura biográfica, que, en el caso de Pla, se haría extensiva a todo su memorialismo. Ese acercamiento a la literatura se substanciaría por una parte en el trabajo estilístico y por el otro en la adopción de técnicas novelísticas. La excelencia de su estilo constituye ya un lugar común de la crítica, que ha destacado abundantemente su capacidad para captar, de manera altamente original, los matices más representativos de personajes, ambientes o paisajes. Bien se podría aplicar a Pla lo que Leon Edel observó en Strachey: "su genio para comprimir en una sola frase ciertos aspectos de una persona [...], la habilidad con la que atrapa el incidente y el detalle con el fin de arrojar

\footnotetext{
${ }^{8}$ En una en concreto califica esta obra como prodigiosa, y la equipara con las Conversaciones con Goethe de Eckermann (Pla, 1984: 436-437).

${ }^{9}$ Por una parte estarían la biografías estrictas, dedicadas a Francesc Cambó (O.C. 25), Joan Maragall, Josep Pijoan i Francesc Pujols (Tres biografies, O.C.10,), Manolo Huguet, Santiago Rusiñol i Joaquim Mir (Tres artistes, O.C. 14), i Rafel Puget, Jacint Puget i l'escultor Josep Llimona (Tres senyors, O.C. 19,). Por otra parte, estarían las semblanzas biográficas y los retratos, presentes en los quatro volumenes de Homenots (O.C. 11, 16, 21 i 29) y en Retrats de passaport (O.C. 17), El passat imperfecte (O.C. 33) y Itàlia i el mediterrani (O.C. 27).
} 
luz sobre una escena o para poner de relieve una personalidad; sobre todo el ingenio y la vivacidad de su prosa" (Edel 1990:149) ${ }^{10}$.

Respecto a la aproximación a las maneras novelísticas por parte de Pla, aunque se trate de un tema menos estudiado, ha sido también señalado por algunos de sus más importantes exégetas. Así, Claudio Guillem, en el estudio que dedica a los Homenots, destaca el uso que Pla hace de recursos propios de la ficción literaria:

El uso del diálogo, del monólogo dramático, de la anécdota extensa, del suceso narrado con la inmediatez y densidad del presente, de lo que acontece ahora, atribuyen a la semblanza rasgos y virtudes de la novela (Guillén 1982: 285-286).

Todas estas características se podrían hacer extensivas al resto del biografismo planiano, y presentan importantes semejanzas con las "biografías noveladas" que la nueva biografía puso de moda.

Quisiéramos aludir a otro aspecto de la hibridación literaria de la escritura planiana: la problematización del pacto referencial. Lluís Bonada (1985) alude a ello al observar la gran ascendencia que Stendhal tenía sobre el escritor catalán. Junto con el antisentimentalismo, la naturalidad y el gusto por lo concreto y los detalles, Bonada resalta una característica de la escritura estendhaliana que también influyó en Pla y que aquí nos interesa especialmente: la gran libertad con la que trata las fechas, y en general, la información referencial que maneja (Bonada 1985: 152). Pero quien ha profundizado más en esta cuestión es Xavier Pla, que en el capítulo final de su libro Josep Pla, ficció autobiogràfica i veritat literària observa cómo sus textos presentan abundantes elementos autoficcionales. Aunque la escritura de Pla pretende ser veraz, no duda, en determinadas ocasiones, en hacer uso de recursos imaginativos o introspectivos propios de la ficción novelesca en aras de la expresividad literaria.

En las biografías también es posible encontrar algún ejemplo esta imaginación novelesca. En el homenot dedicado a Josep Carner, cuando Pla evoca los paseos que daban juntos por la Génova de los años veinte, acude a su memoria la figura del escritor genovés Giuseppe Manzini, uno de los fundadores de la nación italiana:

Quan el treball consular s'acabava, sortíem al carrer. Era cap al tard. Pujàvem lentament els pòrtics alterosos i una mica freds de la Via XX Settembre, arribàvem a la Piazza di Ferrari, entràvem a la galería de tant de sabor vuitcentista de darrera el Teatre Carlo Felice — semblava, en aquella llum de claraboia, que se'ns havia d'aparèixer Giuseppe Manzini-, dèiem un mot al llibrer socialista, divagàvem (Pla 1972: 250).

Respecto al uso de técnicas de análisis psicológico, Jordi Amat observa que ni el Cambó ni la Vida de Manolo encajan en el modelo de biografías de Ludwig, Maurois, Zweig o Strachey, que se caracterizarían por el uso de "la psicoanàlisi com a mecanisme d'exploració de la intimitat dels individus i l'ús de tècniques narratives que possibilitaven la construcció literària de personatges complexos" (Amat 2006: 99) ${ }^{11}$. Pla, ciertamente, muy

\footnotetext{
${ }^{10}$ No hay que perder de vista tampoco que, a pesar de estas semejanzas, existen importantes diferencias entre los dos: la ironía y contención del inglés bien poco tiene que ver con la contundencia y el humor que Pla usa a menudo en su prosa. Es ésta una cuestión que merecería un estudio más detallado.

${ }^{11}$ Para Amat, el modelo de Pla sería mucho más clásico: las anteriormente citadas Conversaciones con Goethe de Eckermann y la Vida de Samuel Johnson, de James Boswell.
} 
rara vez hace uso de conceptos ni técnicas de inspiración psicoanalíticos, dado que practica por encima de toda una literatura de observación ${ }^{12}$. En sus biografías la información psicológica se obtiene, en la mayoría de los casos, a partir del conocimiento directo de los personajes, que son caracterizados mediante la focalización externa, fijando su atención en las conversaciones, la apariencia física y la manera de actuar de los personajes. Eso es así incluso en sus novelas y narraciones. Sin embargo, eso no impide que su literatura no tenga momentos de gran penetración psicológica, y que sus personajes no presenten una gran riqueza de matices. Quisiéramos ilustrarlo con un ejemplo de los muchos posibles, el "retrat de passaport" dedicado al periodista ampurdanés Josep Ferrer:

No era pas home que s'aturés persistentment davant les coses, que els donés la volta d'una manera lenta, insidiosa, mórbida. Tirava al dret com un boig, amb una crispació esquinçada i febricitant: semblava un pàl·lid fantasma desvetllat per una força admirable i cega [...] Tot això portaría a creure que fou simplement un sensual -és a dir, una criatura sense resistència posible davant els propis estats de buidor, de solitud o de tedi (Pla 1970b: 20-21).

Por último, podríamos encontrar otro vínculo posible entre la nueva biografía y el biografismo planiano en el uso continuado de las biografías como vía de acceso a la historia. Resulta difícil no pensar que la gran popularidad de que el género gozó en la etapa de formación de Pla no le influyera en su decantación por él. Así mismo, creemos que se puede establecer un paralelismo entre la obra cumbre de Strachey, Eminent Victorians, y los Homenots de Josep Pla, quintaesencia de su biografismo. En ambos casos se lleva a cabo la reconstrucción de una época a través de las semblanzas de algunos de sus representantes más conspicuos. A pesar de las enormes diferencias de contexto nacional, tanto Pla como Strachey mantienen un admirable equilibrio entre el respeto al personaje y la mirada crítica ${ }^{13}$. Cierto que en Eminent Victorians la unidad del conjunto es mayor, mientras que en las cuatro series de Homenots se observa una mayor diferencia de criterio, que va de la admiración incondicional a figuras fundacionales de la Cataluña contemporánea como Pompeu Fabra, Prat de la Riba, Francesc Cambó o Josep Carner, a la displicencia cuando no vituperio que le merece el poeta Salvat-Papasseit. Entre medias, se extiende toda una gama de posibilidades. Aunque para encontrar al Pla más caustico tendríamos que acudir a sus Retrats de passaport, donde personajes como Cristòfor de Doménech, Xavier Viura o Gabriel Miró son caricaturizados sin piedad.

Al final de este recorrido en paralelo por la obra de Lytton Strachey y Josep Pla podemos sacar ya algunas conclusiones. Se trata de autores con una personalidad creadora diferenciada, pero también con importantes puntos de contacto. El "mestre insuperable de la biografia”, como lo llamó Pla, renovó el género gracias a su mirada crítica y a su instinto literario, atento a los detalles, a la síntesis dramática, a la ironía. La eficacia narrativa de sus textos y

\footnotetext{
${ }^{12}$ Sin embargo, en alguna ocasión sí que se dejó tentar por el instrumental freudiano, como en el retrato de Josep Carner: "El prodigiós joc verbal de la seva conversa, réflex del riquíssim joc verbal de la seva poesía, és potser l'evasió d'un erotisme sense objecte tangible on projectar-lo, sobrant" (Pla 1972: 240).

${ }^{13}$ Las colecciones de biografías y los escasos practicantes del memorialismo catalán de las primeras décadas del siglo XX eran conscientes de la importante dimensión identitaria de sus obras. Pla no fue una excepción, y lo recuerda a menudo en sus prólogos, como en este de la segunda serie de los Homenots: "L'única manera de lluitar contra la terrible invasió de l'oblit, de crear una memòria col·lectiva, és recordar, infatigablement, el que alguns homes -és a dir, el poble- han fet una mica més enllà dels interessos particulars, immediats i petits" (Pla 1970a: 7).
} 
su penetración psicológica, acortó las distancias entre biografía y novela. Todas estas son cualidades presentes también en la obra de Josep Pla. Cuando Pla conoció la obra de Strachey y la de los otros autores de la nueva biografía, era un joven escritor que había decidido ya el rumbo que su obra debía tomar: el del memorialismo. En su voluntad de dejar testimonio de su época, las biografías ya habían empezado a ocupar un papel importante, que a lo largo de su producción no haría sino crecer. Parece razonable pensar que ese conocimiento pudo ser para él una confirmación en la opción literaria que había elegido, así como un estímulo a lo largo de los años de insistencia en el género biográfico.

\section{Referencias bibliográficas}

AMAT, Jordi (2006): “Josep Pla, també biògraf”. Revista de Catalunya 216: 94-107.

BALAGUER, Enric (2012): "El «poeta nacional» com a tòtem". Magí Sunyer i Montserrat Corretger (eds.), Mitologia, simbologia i literatura, Barcelona: PAM, pp.145-166.

BONADA, Lluís (1985): "L'inici d' El quadern gris de Pla”. Narcís Garolera, (ed.), Anàlisis i comentaris de textos literaris catalans. Barcelona: Curial, pp.150-165.

BURDIEL, Isabel (2000), "La dama de blanco. Notas sobre la biografia histórica". Isabel Burdiel i M. Pérez Ledesma (eds.), Liberales, agitadores y conspiradores. Madrid: Espasa.

CASALS, Glòria (1986): "Notes sobre les biografies de Josep Pla". Els Marges 33: 120-130.

EDEL, Leon (1990): Vidas ajenas. Principia Biographica. México: FCE.

Guillén, Claudio (1982): "Sobre las semblanzas de Josep Pla", in Actes del II Col-loqui d'Estudis catalans a Nord-Amèrica. Barcelona: PAM, pp. 263-291.

IRIBARREN, Teresa (2007): "La magnitud del magnetisme de Maurois", in La projecció social de l'escriptor en la literatura catalana, Lleida: Punctum, /Grup d'Estudis de Literatura Contemporània.

MAdelÉnAt, Daniel (1984): La biographie. París: PUF.

PlA, Josep (1970a): Tres artistes. Obra Completa, 14. Barcelona: Destino.

PLA, Josep (1970b): Retrats de passaport. Obra completa,17. Barcelona: Destino.

PlA, Josep (1972): Homenots, tercera sèrie. Obra Completa, 21. Barcelona: Destino.

PlA, Josep (1975): Homenots, quarta sèrie. Obra Completa, 29. Barcelona: Destino.

PLA, Josep (1977): El passat imperfecte. Obra Completa 33. Barcelona: Destino.

PlA, Josep (1983): Caps i puntes. Obra completa, 43. Barcelona: Destino.

PlA, Josep (1984): Darrers escrits. Obra completa 44, Barcelona: Destino.

PlA, Xavier (1997): Josep Pla, ficció autobiogràfica i veritat literaria. Barcelona: Quaderns Crema.

SERRANO ASENJO, Enrique (2002): Vidas oblicuas: Aspectos teóricos de la nueva biografía en España (1928-1936). Zaragoza: Prensas Universitarias de Zaragoza.

SoldEvilA, Carles (1956-57): prólogo a Emile Ludwig, Obras completas. Barcelona: Editorial Juventud: 17-18.

STRACHEY, Lytton (1998): Victorianos eminentes. Madrid: Valdemar.

Woolf, Virginia (1967): Collected Essays, 3. Londres: Hogarth. 